\title{
Loss of food fermentation in Westernized diet: a risk factor for severe COVID-19?
}

\author{
Jean Bousquet ${ }^{1}$, Josep Anto ${ }^{2}$, Wienczyslawa Czarlewski ${ }^{3}$, Tari Haahtela ${ }^{4}$, Susana Fonseca ${ }^{5}$, \\ Guido Iaccarino ${ }^{6}$, Hubert Blain ${ }^{7}$, Cezmi Akdis ${ }^{8}$, and Torsten Zuberbier ${ }^{9}$ \\ ${ }^{1}$ Université Versailles, St-Quentin-en-Yvelines \\ ${ }^{2}$ ISGLoBAL \\ ${ }^{3}$ Medical Consulting \\ ${ }^{4}$ Helsinki University Hospital \\ ${ }^{5}$ GreenUPorto - Sustainable Agrifood Production Research Centre \\ ${ }^{6}$ Federico II University Hospital \\ ${ }^{7} \mathrm{CHU}$ Montpellier \\ ${ }^{8}$ University of Zurich \\ ${ }^{9}$ Charité Universitätsmedizin Berlin
}

July 20, 2020

To the Editor,

The fermentation process, born as a preservation method in the Neolithic age, enabled humans to eat notso-fresh food and to survive. ${ }^{1}$ Fermented foods are "foods or beverages made via controlled microbial growth (including lactic acid bacteria (LAB)) and enzymatic conversions of food components." 2 Not all fermented foods contain live cultures, as some undergo further processing after fermentation: pasteurization, smoking, baking, or filtration. These processes kill or remove the live microorganisms in foods such as soy sauces, bread, most beers and wines as well as chocolate. Live cultures can be found in fermented vegetables and fermented milk (fermented sour milk, yoghurt, probiotics, ...). The westernized diet is lacking many traditional fermented foods. ${ }^{3}$

The gut microbiota has an inter-individual variability due to genetic predisposition and diet ${ }^{3}$. Some foods like cabbage can be fermented by the gut microbiota. ${ }^{4}$ The westernized diet has been associated with changes in the gut microbiome. ${ }^{5}$

In this Rostrum, we consider loss of food fermentation either as a reduction of fermented food consumption in the diet or as a change in the microbiome leading to a reduction of fermentation of foods in the gut. This paper is based on the hypothesis that diet may partly explain differences in COVID-19 death rates within and between countries. ${ }^{6}$

\section{Diet and heterogeneity of COVID-19 death rates between and within countries}

Large differences exist when assessing death rates between and within countries. Most countries with a very low COVID-19 death rate (Asia, Africa, Central European countries, the Balkans or the Middle East) are well-known to have a diet containing fermented vegetables.

To test the potential role of fermented foods in the COVID-19 mortality in Europe, an ecological study, the European Food Safety Authority (EFSA) Comprehensive European Food Consumption Database, was used to study country consumption of fermented vegetables, pickled/marinated vegetables, fermented milk, 
yoghurt and fermented sour milk. ${ }^{7}$ Of all the variables considered, including confounders, only fermented vegetables reached statistical significance with the COVID-19 death rate per country. For each g/day increase in consumption of fermented vegetables of the country, the mortality risk for COVID-19 was found to decrease by $35.4 \%$.

Another diet component potentially relevant in the COVID-19 mortality may be the food supply chain and traditional groceries that may be inferred from death rates in Italian regions (Figure 1B). ${ }^{8}$ The impact of the long supply chain of food on health is measurable by an increase in metabolic syndrome and insulin resistance ${ }^{9}$. Therefore, areas that are more prone to short supply food and traditional groceries may have been able to better tolerate COVID-19 with a lower death toll.

In Switzerland, the French- and Italian-speaking cantons had a far higher death rate than the German-speaking ones (Figure 3) (Office fédéral de la santé publique, Switzerland,https://www.bag.admin.ch/bag/fr/home.html). It may be proposed that the high-death rate cantons were contaminated by French and Italian people. However, the Mulhouse airport serves the region of Basel (Switzerland), the Haut-Rhin department (France) and the region of Freiburg (Germany). There was a COVID-19 outbreak in the Haut-Rhin department, in particular in Mulhouse and Colmar. The death rate for COVID-19 (May 20, 2020) was 935 per million inhabitants in France but only 10 to 25 in Switzerland and 7 in Germany (Figure 2).

\section{COVID-19: ACE2 binding and insulin resistance.}

The angiotensin-converting enzyme 2 (ACE-2) is part of the dual system, the renin-angiotensin-system (RAS), and includes the ACE-Angiotensin-II- $\mathrm{AT}_{1} \mathrm{R}$ axis. $\mathrm{AT}_{1} \mathrm{R}$ is involved in most Angiotensin II effects, including oxidative stress generation, pro-inflammatory and pro-fibrotic effects in the respiratory system as well as insulin resistance. ${ }^{10,11}$ SARS-CoV-2 binds ${ }^{12}$ and downregulates ACE-2, enhancing the $\mathrm{AT}_{1} \mathrm{R}$ axis 13. It is likely to be associated with insulin resistance. ${ }^{14}$

\section{Microbiome, fermented food and lacobacilli.}

Humans possess two protective layers of biodiversity, and the microbiome has been proposed as an important actor of COVID-19 ${ }^{15}$. The environment (outer layer) affects our lifestyle, shaping the microbiome (inner layer). ${ }^{16}$ Many fermented foods contain living microorganisms and modulate the intestinal microbiome. $2,17-20$

The composition of microbiomes varies in different regions of the world. ${ }^{21}$ Urbanization in western countries was associated with changes in the gut microbiome and with intestinal diversity reduction. ${ }^{3,5,22-24}$ Westernized food in Japan led to changes in the microbiome and in insulin resistance. ${ }^{25}$ The gut microbiome of westernized urban Saudis had a lower biodiversity than that of the traditional Bedouin population. ${ }^{26}$ Fast food consumption was characterised by reduced Lactobacilli in the microbiome. ${ }^{27}$

The links between gut microbiome, inflammation, obesity and insulin resistance are being observed but further large studies are needed for a definite conclusion. ${ }^{28-30}$

Some COVID-19 patients have intestinal microbial dysbiosis ${ }^{31}$ with decreased probiotics such as Lactobacillus and Bifidobacterium ${ }^{32}$. Many bacteria are involved in the fermentation of vegetables but most traditional

foods with live bacteria in the low-death rate countries are based on LAB fermentation. ${ }^{33-37}$ Lactobacilli are among the most common microorganisms found in milk and milk products ${ }^{38-40}$.

\section{Effect of lactic acid bacteria in insulin resistance and related diseases.}

Insulin resistance and Lactobacilus.

Hundreds of studies have attempted to find an efficacy of LAB on insulin resistance-associated diseases. However, most of them are underpowered or have some methodological flaws. Moreover, not all LAB strains have the same action on insulin resistance ${ }^{41}$ and new better designed studies with the appropriate LAB are required. A large meta-analysis found that the intake of probiotics resulted in minor but consistent 
improvements in several metabolic risk factors in subjects with metabolic diseases, and in particular in insulin resistance $^{42}$. Another recent meta-analysis found that an oral supplementation with probiotics or synbiotics has a small effect in reducing waist circumference but no effect on body weight or body mass index (BMI) ${ }^{43}$. Kefir, a fermented milk product, was not found to be more effective than yoghurt in the glycemic control of obesity, possibly because there are insufficient differences between both ${ }^{44}$. Nrf2 may be involved in diseases associated with insulin-resistance ${ }^{45-47}$. "Ancient foods", and particularly those containing Lactobacillus , activate $\mathrm{Nrf2}^{48}$. The microbiome is highly related to insulin resistance.

\section{Lactobacillus and Nrf2}

In mice, several strains of Lactobacillus were found to regulate Nrf2 in models of ageing ${ }^{49}$, cardioprotective effects $^{50}$, and non-alcoholic fatty acid liver disease ${ }^{51}$. Lactobacillus plantarum CQPC11 - isolated from Sichuan pickled cabbages - antagonizes oxidation and ageing in mice ${ }^{52}$. Lactobacillus protects against ulcerative colitis by modulation of the gut microbiota and Nrf2/Ho-1 pathway ${ }^{53}$. The sugary kefir strain, Lactobacillus maliAPS1, \soutameliorated ameliorates? hepatic steatosis by regulation of Nrf2 and the gut microbiota in rats ${ }^{54}$. In vitro studies have also found an effect of Lactobacilli mediated by Nrf2 ${ }^{55-57}$. Interestingly, the synbiotic combination of prebiotic grape pomace extract and probioticLactobacillus sp. \soutreduced reduces? intestinal inflammatory markers. ${ }^{58}$

Coronavirus disease in animals and lactic acid bacteria.

The porcine epidemic diarrhea virus (PEDV), or Transmissible Gastroenteritis Coronavirus Infection (TGEV), are worldwide-distributed coronaviruses. Low levels of Lactobacillus were found in the intestine of piglets infected by TGEV ${ }^{59}$ or PEDV.Lactobacillus inhibits PEDV or TGEV effects in vitro ${ }^{60,61}$.

Westernized food and fermented vegetables.

Westernized diets contain a reduced amount of fermented vegetables ${ }^{5,62}$ and may be prone to increasing insulin resistance and thereby severe COVID-19. The transcription factor Nrf2 may be at the centre of the regulatory pathways (Figure 3 ).

\section{COVID-19 and food fermentation .}

Although nutritional epidemiology has been criticized on several fronts - its inability to measure diet accurately and its reliance on observational studies to address etiologic questions ${ }^{63}$ - there seems to be sufficient evidence to raise several conclusions (to be tested appropriately).

Many factors may play a role in the extension and severity of COVID-19. Diet may represent only one of the possible causes of COVID-19 severity (Table 1). The effects of the microbiome ${ }^{64}$ and $\operatorname{diet}^{6}$ on SARS-CoV-2 infection suggest that their role in the gut could be a target for COVID-19 interventions. It is proposed that countries with a large consumption of traditional LAB-fermented vegetables are those showing lower COVID-19 death rates. This hypothesis should be confirmed by experimental studies (Box 1). If certain foods are found to be associated with a prevention of COVID-19 prevalence or severity, it may be of interest to study their LAB composition in order to eventually find some common mechanisms and targets for therapy.

Jean Bousquet, MD, Charité, Universitätsmedizin Berlin, Humboldt-Universität zu Berlin, and Berlin Institute of Health, Comprehensive Allergy Center, Department of Dermatology and MACVIA-France, Montpellier, France Allergy, Berlin, Germany

Josep M Anto, MD, ISGlobAL, Centre for Research in Environmental Epidemiology (CREAL), IMIM (Hospital del Mar Research Institute), Universitat Pompeu Fabra (UPF), CIBER Epidemiología y Salud Pública (CIBERESP), Barcelona, Spain

Wienczyslawa Czarlewski, MD, Medical Consulting Czarlewski, Levallois, and MASK-air, Montpellier France.

Tari Haahtela, MD, Skin and Allergy Hospital, Helsinki University Hospital, Helsinki, Finland. 
Susana C Fonseca, PhD, GreenUPorto - Sustainable Agrifood Production Research Centre, DGAOT, Faculty of Sciences, University of Porto, Campus de Vairão, Rua da Agrária, Porto, Portuga

Guido Iaccarino, MD, Federico II University, Department of Advanced Biomedical Sciences, Napoli, Italy.

Hubert Blain, MD, Pole Gérontologie, University Hospital, Montpellier University, MUSE, Montpellier.

Cezmi A Akdis, MD, Swiss Institute of Allergy and Asthma Research (SIAF), University of Zurich, Davos, Switzerland

Torsten Zuberbier, MD, Charité, Universitätsmedizin Berlin, Humboldt-Universität zu Berlin, and Berlin Institute of Health, Comprehensive Allergy Center, Department of Dermatology, Berlin Germany

JB designed the concept. All the other authors reviewed the concept and approved the paper

\section{References}

1. Peters A, Krumbholz P, Jager E, et al. Metabolites of lactic acid bacteria present in fermented foods are highly potent agonists of human hydroxycarboxylic acid receptor 3. PLoS Genet 2019;15:e1008145.

2. Marco ML, Heeney D, Binda S, et al. Health benefits of fermented foods: microbiota and beyond. Curr Opin Biotechnol 2017;44:94-102.

3. Bibbo S, Ianiro G, Giorgio V, et al. The role of diet on gut microbiota composition. Eur Rev Med Pharmacol Sci 2016;20:4742-9.

4. Tian S, Liu X, Lei P, Zhang X, Shan Y. Microbiota: a mediator to transform glucosinolate precursors in cruciferous vegetables to the active isothiocyanates. J Sci Food Agric 2018;98:1255-60.

5. Wilson AS, Koller KR, Ramaboli MC, et al. Diet and the Human Gut Microbiome: An International Review. Dig Dis Sci 2020;65:723-40.

6. Bousquet J, Anto JM, Iaccarino G, et al. Is diet partly responsible for differences in COVID-19 death rates between and within countries? Clin Transl Allergy 2020;10:16.

7. Fonseca S, Rivas I, Romaguera D, et al. Association between consumption of fermented vegetables and COVID-19 mortality at a country level in Europe MEDRXIV/2020/147025 2020.

8. Baker P, Friel S. Food systems transformations, ultra-processed food markets and the nutrition transition in Asia. Global Health 2016;12:80.

9. Santulli G, Pascale V, Finelli R, et al. We are What We Eat: Impact of Food from Short Supply Chain on Metabolic Syndrome. J Clin Med 2019;8.

10. Dalan R, Bornstein SR, El-Armouche A, et al. The ACE-2 in COVID-19: Foe or Friend? Horm Metab Res 2020;52:257-63.

11. Wen H, Gwathmey JK, Xie LH. Oxidative stress-mediated effects of angiotensin II in the cardiovascular system. World J Hypertens 2012;2:34-44.

12. Azkur AK, Akdis M, Azkur D, et al. Immune response to SARS-CoV-2 and mechanisms of immunopathological changes in COVID-19. Allergy 2020;75:1564-81.

13. Sarzani R, Giulietti F, Di Pentima C, Giordano P, Spannella F. Disequilibrium between the Classic Renin-Angiotensin System and Its Opposing Arm in Sars-Cov-2 Related Lung Injury. Am J Physiol Lung Cell Mol Physiol 2020.

14. Bousquet J, Anto J, Czarlewski W, et al. Sulforaphane: from death rate heterogeneity in countries to candidate for prevention of severe COVID-19 Allergy 2020;submitted. 
15. Riggioni C, Comberiati P, Giovannini M, et al. A compendium answering 150 questions on COVID-19 and SARS-CoV-2. Allergy 2020.

16. Ruokolainen L, Lehtimäki J, Karkman A, Haahtela T. Holistic view on health : two protective layers of biodiversity. Ann Zool Fennici 2017;54:39-49.

17. Septembre-Malaterre A, Remize F, Poucheret P. Fruits and vegetables, as a source of nutritional compounds and phytochemicals: Changes in bioactive compounds during lactic fermentation. Food Res Int 2018;104:86-99.

18. Dimidi E, Cox SR, Rossi M, Whelan K. Fermented Foods: Definitions and Characteristics, Impact on the Gut Microbiota and Effects on Gastrointestinal Health and Disease. Nutrients 2019;11.

19. Kok CR, Hutkins R. Yogurt and other fermented foods as sources of health-promoting bacteria. Nutr Rev 2018;76:4-15.

20. De Filippis F, Pasolli E, Ercolini D. The food-gut axis: lactic acid bacteria and their link to food, the gut microbiome and human health. FEMS Microbiol Rev 2020.

21. Mobeen F, Sharma V, Tulika P. Enterotype Variations of the Healthy Human Gut Microbiome in Different Geographical Regions. Bioinformation 2018;14:560-73.

22. Segata N. Gut Microbiome: Westernization and the Disappearance of Intestinal Diversity. Curr Biol 2015;25:R611-3.

23. Vangay P, Johnson AJ, Ward TL, et al. US Immigration Westernizes the Human Gut Microbiome. Cell 2018;175:962-72 e10.

24. Zuo T, Kamm MA, Colombel JF, Ng SC. Urbanization and the gut microbiota in health and inflammatory bowel disease. Nat Rev Gastroenterol Hepatol 2018;15:440-52.

25. Yamashita M, Okubo H, Kobuke K, et al. Alteration of gut microbiota by a Westernized lifestyle and its correlation with insulin resistance in non-diabetic Japanese men. J Diabetes Investig 2019;10:1463-70.

26. Angelakis E, Yasir M, Bachar D, et al. Gut microbiome and dietary patterns in different Saudi populations and monkeys. Sci Rep 2016;6:32191.

27. Mitsou EK, Kakali A, Antonopoulou S, et al. Adherence to the Mediterranean diet is associated with the gut microbiota pattern and gastrointestinal characteristics in an adult population. Br J Nutr 2017;117:164555 .

28. Saad MJ, Santos A, Prada PO. Linking Gut Microbiota and Inflammation to Obesity and Insulin Resistance. Physiology (Bethesda) 2016;31:283-93.

29. Chen X, Devaraj S. Gut Microbiome in Obesity, Metabolic Syndrome, and Diabetes. Curr Diab Rep 2018;18:129.

30. Lee CJ, Sears CL, Maruthur N. Gut microbiome and its role in obesity and insulin resistance. Ann N Y Acad Sci 2020;1461:37-52.

31. Zuo T, Zhang F, Lui GCY, et al. Alterations in Gut Microbiota of Patients With COVID-19 During Time of Hospitalization. Gastroenterology 2020.

32. Xu K, Cai H, Shen Y, et al. [Management of Corona Virus disease-19 (COVID-19): The Zhejiang Experience]. Zhejiang Da Xue Xue Bao Yi Xue Ban 2020;49.

33. Azam M, Mohsin M, Ijaz H, et al. Review - Lactic acid bacteria in traditional fermented Asian foods. Pak J Pharm Sci 2017;30:1803-14.

34. Rhee SJ, Lee JE, Lee CH. Importance of lactic acid bacteria in Asian fermented foods. Microb Cell Fact 2011;10 Suppl 1:S5. 
35. Patra JK, Das G, Paramithiotis S, Shin HS. Kimchi and Other Widely Consumed Traditional Fermented Foods of Korea: A Review. Front Microbiol 2016;7:1493.

36. Jung JY, Lee SH, Jeon CO. Kimchi microflora: history, current status, and perspectives for industrial kimchi production. Appl Microbiol Biotechnol 2014;98:2385-93.

37. Yoon KY, Woodams EE, Hang YD. Production of probiotic cabbage juice by lactic acid bacteria. Bioresour Technol 2006;97:1427-30.

38. Slattery C, Cotter PD, O'Toole PW. Analysis of Health Benefits Conferred by Lactobacillus Species from Kefir. Nutrients 2019;11.

39. Shiby VK, Mishra HN. Fermented milks and milk products as functional foods-a review. Crit Rev Food Sci Nutr 2013;53:482-96.

40. Sanders ME, Merenstein DJ, Reid G, Gibson GR, Rastall RA. Probiotics and prebiotics in intestinal health and disease: from biology to the clinic. Nat Rev Gastroenterol Hepatol 2019;16:605-16.

41. Lee E, Jung SR, Lee SY, Lee NK, Paik HD, Lim SI. Lactobacillus plantarum Strain Ln4 Attenuates Diet-Induced Obesity, Insulin Resistance, and Changes in Hepatic mRNA Levels Associated with Glucose and Lipid Metabolism. Nutrients 2018;10.

42. Koutnikova H, Genser B, Monteiro-Sepulveda M, et al. Impact of bacterial probiotics on obesity, diabetes and non-alcoholic fatty liver disease related variables: a systematic review and meta-analysis of randomised controlled trials. BMJ Open 2019;9:e017995.

43. Suzumura EA, Bersch-Ferreira AC, Torreglosa CR, et al. Effects of oral supplementation with probiotics or synbiotics in overweight and obese adults: a systematic review and meta-analyses of randomized trials. Nutr Rev 2019;77:430-50.

44. Barengolts E, Smith ED, Reutrakul S, Tonucci L, Anothaisintawee T. The Effect of Probiotic Yogurt on Glycemic Control in Type 2 Diabetes or Obesity: A Meta-Analysis of Nine Randomized Controlled Trials. Nutrients 2019;11.

45. Uruno A, Yagishita Y, Yamamoto M. The Keap1-Nrf2 system and diabetes mellitus. Arch Biochem Biophys 2015;566:76-84.

46. Vasileva LV, Savova MS, Amirova KM, Dinkova-Kostova AT, Georgiev MI. Obesity and NRF2-mediated cytoprotection: Where is the missing link? Pharmacol Res 2020;156:104760.

47. Guo Z, Mo Z. Keap1-Nrf2 signaling pathway in angiogenesis and vascular diseases. J Tissue Eng Regen Med 2020;14:869-83.

48. Senger DR, Li D, Jaminet SC, Cao S. Activation of the Nrf2 Cell Defense Pathway by Ancient Foods: Disease Prevention by Important Molecules and Microbes Lost from the Modern Western Diet. PLoS One 2016;11:e0148042.

49. Li B, Evivie SE, Lu J, et al. Lactobacillus helveticus KLDS1.8701 alleviates d-galactose-induced aging by regulating Nrf-2 and gut microbiota in mice. Food Funct 2018;9:6586-98.

50. Xu H, Wang J, Cai J, et al. Protective Effect of Lactobacillus rhamnosus GG and its Supernatant against Myocardial Dysfunction in Obese Mice Exposed to Intermittent Hypoxia is Associated with the Activation of Nrf2 Pathway. Int J Biol Sci 2019;15:2471-83.

51. Zhao Z, Wang C, Zhang L, et al. Lactobacillus plantarum NA136 improves the non-alcoholic fatty liver disease by modulating the AMPK/Nrf2 pathway. Appl Microbiol Biotechnol 2019;103:5843-50.

52. Qian Y, Zhang J, Zhou X, et al. Lactobacillus plantarum CQPC11 Isolated from Sichuan Pickled Cabbages Antagonizes d-galactose-Induced Oxidation and Aging in Mice. Molecules 2018;23. 
53. El-Baz AM, Khodir AE, Adel El-Sokkary MM, Shata A. The protective effect of Lactobacillus versus 5-aminosalicylic acid in ulcerative colitis model by modulation of gut microbiota and Nrf2/Ho-1 pathway. Life Sci 2020;256:117927.

54. Chen YT, Lin YC, Lin JS, Yang NS, Chen MJ. Sugary Kefir Strain Lactobacillus mali APS1 Ameliorated Hepatic Steatosis by Regulation of SIRT-1/Nrf-2 and Gut Microbiota in Rats. Mol Nutr Food Res 2018;62:e1700903.

55. Xu C, Qiao L, Ma L, et al. Biogenic selenium nanoparticles synthesized by Lactobacillus casei ATCC 393 alleviate intestinal epithelial barrier dysfunction caused by oxidative stress via Nrf2 signaling-mediated mitochondrial pathway. Int J Nanomedicine 2019;14:4491-502.

56. Mu G, Li H, Tuo Y, Gao Y, Zhang Y. Antioxidative effect of Lactobacillus plantarum Y44 on 2,2'-azobis(2methylpropionamidine) dihydrochloride (ABAP)-damaged Caco-2 cells. J Dairy Sci 2019;102:6863-75.

57. Kobatake E, Nakagawa H, Seki T, Miyazaki T. Protective effects and functional mechanisms of Lactobacillus gasseri SBT2055 against oxidative stress. PLoS One 2017;12:e177106.

58. Pistol GC, Marin DE, Dragomir C, Taranu I. Synbiotic combination of prebiotic grape pomace extract and probiotic Lactobacillus sp. reduced important intestinal inflammatory markers and in-depth signalling mediators in lipopolysaccharide-treated Caco-2 cells. Br J Nutr 2018:1-15.

59. Xia L, Yang Y, Wang J, Jing Y, Yang Q. Impact of TGEV infection on the pig small intestine. Virol J 2018;15:102.

60. Kumar R, Seo BJ, Mun MR, et al. Putative probiotic Lactobacillus spp. from porcine gastrointestinal tract inhibit transmissible gastroenteritis coronavirus and enteric bacterial pathogens. Trop Anim Health Prod 2010;42:1855-60.

61. Zhang X, Li P, Zheng Q, Hou J. Lactobacillus acidophilus S-layer protein-mediated inhibition of PEDVinduced apoptosis of Vero cells. Vet Microbiol 2019;229:159-67.

62. Raghuvanshi R, Grayson AG, Schena I, Amanze O, Suwintono K, Quinn RA. Microbial Transformations of Organically Fermented Foods. Metabolites 2019;9.

63. Satija A, Yu E, Willett WC, Hu FB. Understanding nutritional epidemiology and its role in policy. Adv Nutr 2015;6:5-18.

64. Kalantar-Zadeh K, Ward S, Kalantar-Zadeh K, El-Omar E. Considering the effects of microbiome and diet on SARS-CoV-2 infection: nantechnology roles. ACSNano 2020:in press.

Table 1: Possible risk factors for COVID-19 infection explaining geographical differences

\begin{tabular}{llll}
\hline & & Individual level & Country/region level \\
\hline A & $\begin{array}{l}\text { Contact with a } \\
\text { SARS-Cov-2 infected } \\
\text { individual } \\
\text { Intensity of social } \\
\text { contacts }\end{array}$ & ++++ & $\begin{array}{l}\text { Case zero identified } \\
+++ \text { e.g. Lombardy }\end{array}$ \\
A & ++ & +++ \\
Antensity of & +++ & ++ \\
occupational contacts & Confinement (level) & +++ & +++ e.g. US versus EU \\
A & Confinement (early & +++ & $\begin{array}{l}\text { Sweden vo Nordic } \\
\text { countries }\end{array}$ \\
& measures) & +++ e.g. UK versus EU
\end{tabular}




\begin{tabular}{|c|c|c|c|}
\hline & & Individual level & Country/region level \\
\hline A & $\begin{array}{l}\text { Climatic conditions } \\
\text { (temperature, humidity) }\end{array}$ & $?$ & $\begin{array}{l}++ \text { Hot and humid } \\
\text { temperature may reduce } \\
\text { infection but epidemic } \\
\text { bursts in Brazil, Peru } \\
\text { and Ecuador }\end{array}$ \\
\hline A & $\begin{array}{l}\text { GDP of a } \\
\text { country/region }\end{array}$ & $?$ & + \\
\hline B & Vitamin D & $?$ & $\begin{array}{l}+ \text { The map of COVID-19 } \\
\text { deaths in Europe and the } \\
\text { low prevalence in Asia } \\
\text { and Africa suggest a role } \\
\text { for diet }\end{array}$ \\
\hline B & Diet & $?$ & + Still unclear \\
\hline B & Food & $++?$ & $\begin{array}{l}\text { + Bibliographic analysis } \\
\text { suggests a role for some } \\
\text { fermented foods. Raw } \\
\text { cabbage can be fermented } \\
\text { in the intestine. Kefir is } \\
\text { largely used in many } \\
\text { low-prevalence countries. }\end{array}$ \\
\hline B & Long food chain supply & $++?$ & $\begin{array}{l}\text { + In Italy and Spain, } \\
\text { there may be an } \\
\text { association with long } \\
\text { chain supply. This may } \\
\text { be relevant since food } \\
\text { quality differs. }\end{array}$ \\
\hline B & $\begin{array}{l}\text { Traditional fermented } \\
\text { food (example of food) }\end{array}$ & $++?$ & $\begin{array}{l}++ \text { This may be a } \\
\text { relevant issue. In former } \\
\text { Eastern European } \\
\text { countries, in the Balkans, } \\
\text { in Africa, in many Asian } \\
\text { countries with } \\
\text { low-COVID-19 } \\
\text { prevalence, traditional } \\
\text { fermented foods are } \\
\text { common (in line with } \\
\text { short food chain supply) }\end{array}$ \\
\hline B & Air pollution & $+?$ & $+?$ \\
\hline B & Underserved area & ++ & ++ \\
\hline $\mathrm{C}$ & Age & +++ & \\
\hline $\mathrm{C}$ & $\begin{array}{l}\text { Comorbidities (severity } \\
\text { of COVID-19) }\end{array}$ & +++ & ++ \\
\hline $\mathrm{C}$ & Sex & ++ & \\
\hline $\mathrm{C}$ & Institutionalized person & ++ & \\
\hline
\end{tabular}

Text Box:

Future research areas:

- Mouse models of COVID to investigate the effects of diet, sulforaphane and similar compounds. 
- Cellular experiments for the in depth investigation of sulforaphane.

- Case control studies.

- Investigation of synergistic effects with other dietary factors and vitamins such as short chain fatty acids, omega 3, vitamin D.

- Identification of the most potent LAB/probiotic strains.

- Multiple omics metabolome analyses of different stages of COVID patients.

- Clinical trials with fermented foods or LABs and other probiotics to prevent severe COVID-19.

- Clinical trials with fermented foods or LABs and other probiotics to reduce severity of COVID-19.

Figure 1: Differences in death rates between Italian regions (July 13, 2020)

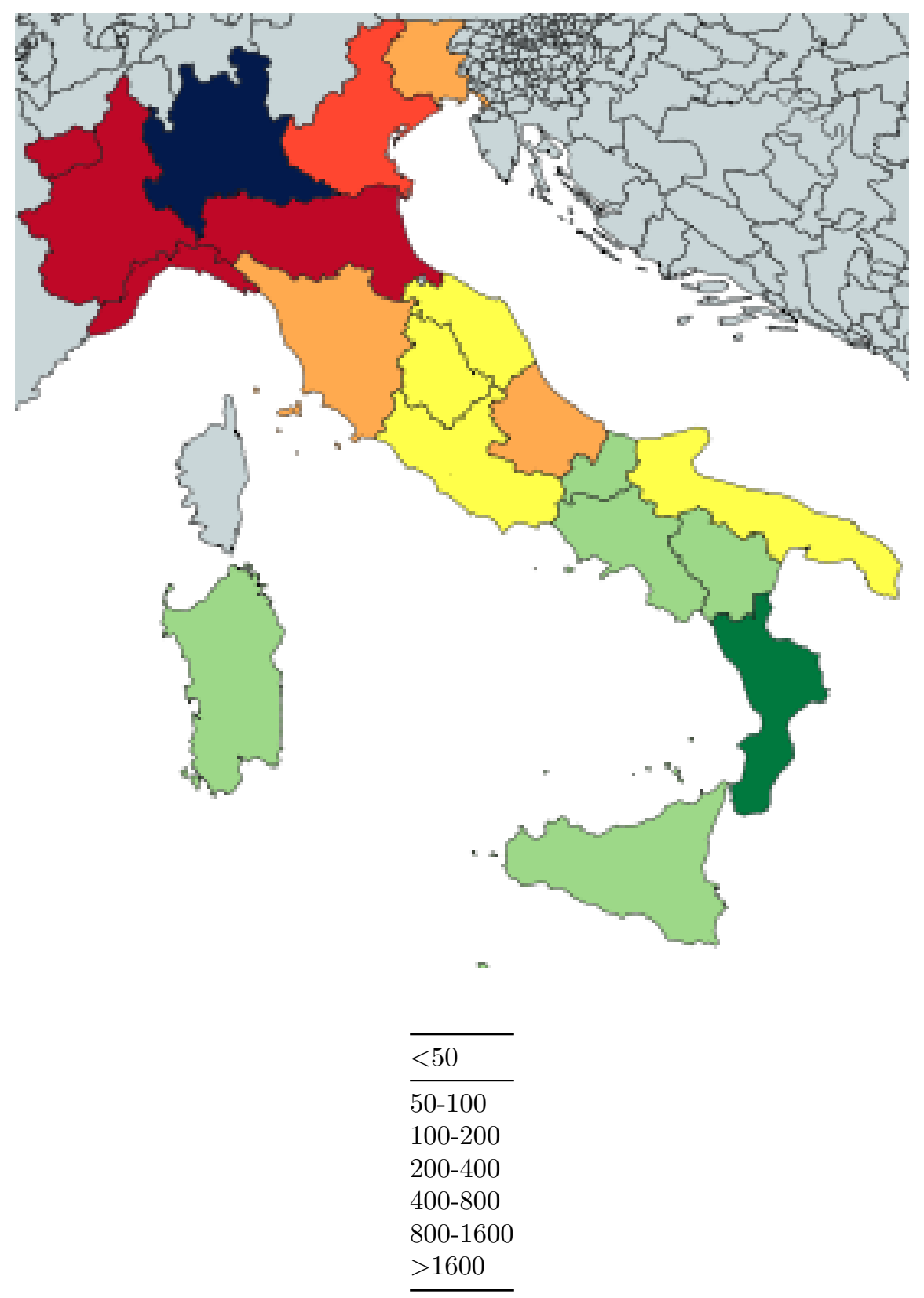




\section{Death rate per million}

Figure 2: Regional differences of death rates between Switzerland, France and Germany (May 20)

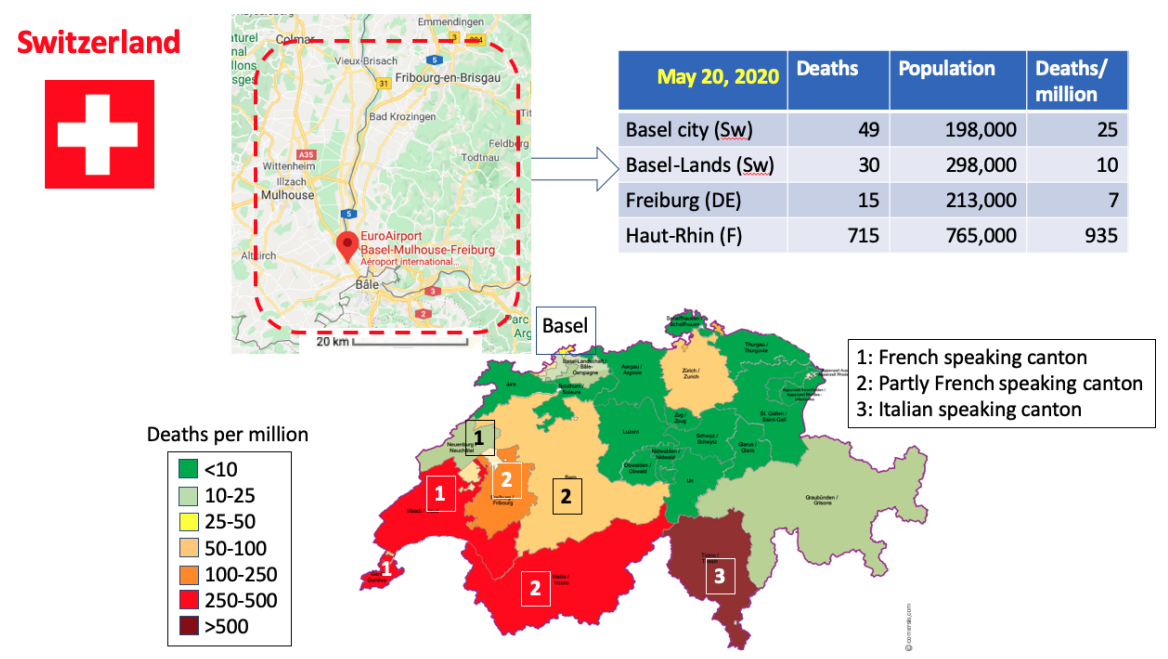

Figure 3: Central role of Nrf2 in the impact of fermented vegetables on COVID-19 severity . SARS-CoV-2 downregulates ACE2, inducing an increased insulin resistance associated with oxidative stress through the $\mathrm{AT}_{1} \mathrm{R}$ pathway. Fermented vegetables are often made from Brassica vegetables that release glucoraphanin converted by the plant or by the gut microbiome into sulforaphane which activates Nrf2 and subsequently reduces insulin intolerance. Fermented vegetables have a high content of Lactobacillus that can activate Nrf2 and impact the microbiome.

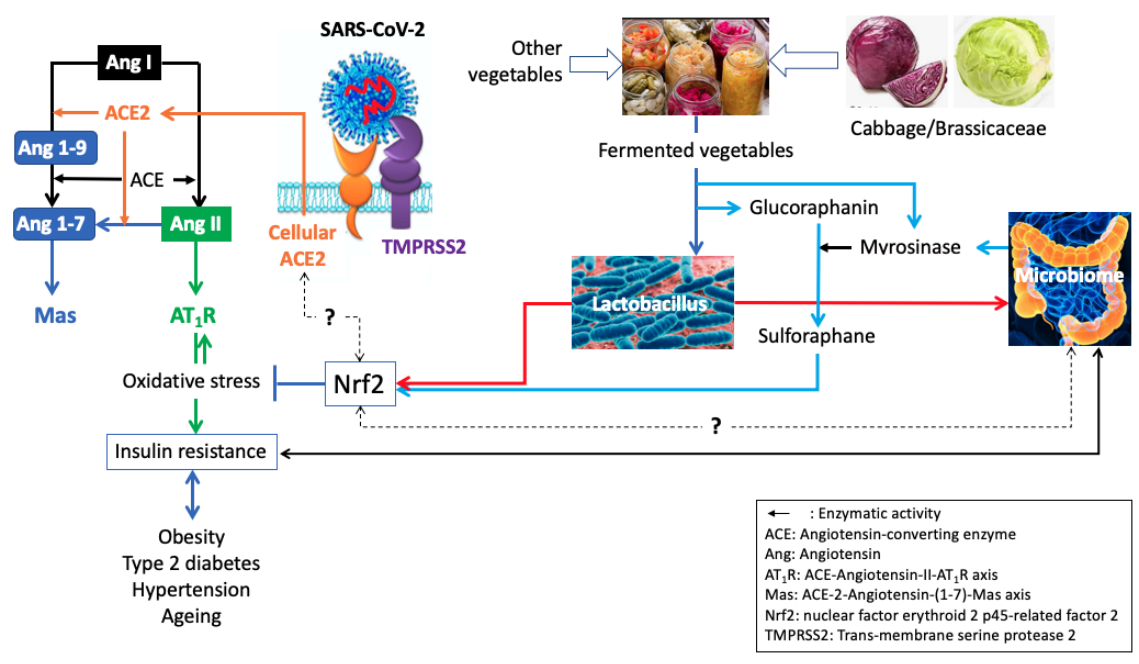

\section{Hosted file}

Figures.pptx available at https://authorea.com/users/322406/articles/470834-loss-of-foodfermentation-in-westernized-diet-a-risk-factor-for-severe-covid-19 